Journal Club

Editor's Note: These short reviews of recent JNeurosci articles, written exclusively by students or postdoctoral fellows, summarize the important findings of the paper and provide additional insight and commentary. If the authors of the highlighted article have written a response to the Journal Club, the response can be found by viewing the Journal Club at www.jneurosci.org. For more information on the format, review process, and purpose of Journal Club articles, please see http://jneurosci.org/content/ preparing-manuscript\#journalclub.

\title{
Emerging Evidence for a Direct Link between EAAT- Associated Anion Channels and Neurological Disorders
}

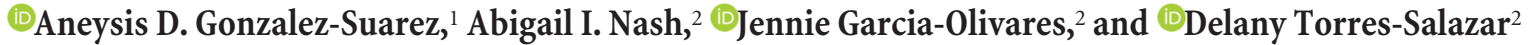 \\ ${ }^{1}$ Yale University School of Medicine, Interdepartmental Neuroscience Program, New Haven, Connecticut 06510, and ${ }^{2}$ National Institute of Mental Health, \\ National Institutes of Health, Bethesda, Maryland 20892 \\ Review of Parinejad et al.
}

Excitatory amino acid transporters (EAATs) are membrane proteins that control excitatory synaptic transmission in the brain (Bergles et al., 1999; Danbolt, 2001; Robinson and Jackson, 2016). As classical secondary active transporters, which use the energy stored within ion gradients to drive substrate translocation, EAATs transport glutamate against its concentration gradient into neurons and glia. To accomplish this, they couple the influx of each glutamate molecule to the influx of two or three sodium ions and one proton and the efflux of one potassium ion (Danbolt, 2001). Dysfunctional glutamate clearance can lead to increased extracellular glutamate concentrations, causing prolonged activation of glutamate receptors and increases in intracellular calcium, resulting in neuronal excitotoxicity. Thus, deficient glutamate uptake is linked to several neurological disorders, including epilepsy, amyotrophic lateral sclerosis, Alzheimer's disease, and Parkinson's disease

\footnotetext{
Received Sept. 19, 2016; revised Nov. 7, 2016; accepted Nov. 9, 2016.

We thank the Intramural Research Program and the office of Fellowship and Training from the National Institute of Mental Health; and Dr. Adam Thomas for critically reading the manuscript and providing helpful comments.

The authors declare no competing financial interests.

Correspondence should be addressed to Dr. Delany Torres-Salazar, Laboratory of Molecular and Cellular Neurobiology, National Institute of Mental Health, National Institutes of Health, 35 Convent Drive, Room 3A-207, Bethesda, MD 20892-1381. E-mail: delany.torressalazar@nih.gov.

DOI:10.1523/JNEUROSCI.2947-16.2017

Copyright $\odot 2017$ the authors $\quad 0270-6474 / 17 / 370241-03 \$ 15.00 / 0$
}

(Danbolt, 2001; Nakagawa and Kaneko, 2013).

In addition to clearing glutamate, EAATs mediate an anion-selective conductance (Fairman et al., 1995), which arises from the diffusion of permeable anions through a glutamate-activated pore within the transporter (Fahlke et al., 2016). Emerging evidence suggests that this EAAT-mediated anion conductance plays a significant role in glutamatergic synaptic transmission. In retinal cells, EAATs act as presynaptic sensors that dampen glutamate release by hyperpolarizing the presynaptic terminal through activation of EAAT-mediated anion currents (Picaud et al., 1995; Veruki et al., 2006; Wersinger et al., 2006).

Several studies have suggested that disruption in EAAT-mediated anion permeation are linked to neurological conditions. For example, a missense mutation leading to arginine substitution for proline (P290R) in EAAT1 (a glial isoform) was identified in a patient with episodic ataxia Type 6, a condition characterized by progressive impairment of coordination and balance and sporadic episodes of hemiplegia, symptoms shown by the patient. This mutation reduced surface expression of EAAT1 and glutamate uptake in vitro, but because there are currently no techniques for assessing EAAT1 activity directly in patients, the authors were unable to link the mutation to disrupted glu- tamate uptake in the patient (Jen et al., 2005).

More recently, Stacey et al. (2010) examined a Drosophila knock-out $\left(\mathrm{EAAT} 1{ }^{\mathrm{KO}}\right)$ and found that the typical full-body peristaltic contractions observed in wild-type larvae were significantly reduced in the EAAT $1{ }^{\mathrm{KO}}$, suggesting that EAAT1 is essential for peristaltic motility. Interestingly, despite showing reduced peristaltic contractions, EAAT1 ${ }^{\mathrm{KO}}$ larvae did not show episodes of paralysis (Stacey et al., 2010). These observations suggest that the paralysis that Jen et al. (2005) linked to the P290R mutation may not solely stem from decreased EAAT1-mediated glutamate uptake, which is absent in the knock-out.

An alternative possibility is that disruption of an EAAT function other than glutamate transport might be responsible for episodes of paralysis. Indeed, Winter et al. (2012) investigated the biophysical properties of anion conduction in the hEAAT1 ${ }^{\text {P290R }}$ mutant, and concluded that reduced glutamate uptake was accompanied by an increase in the anion channel open probability. Using site-directed mutagenesis to probe structure-function relationships, several groups have characterized mutations that disrupt substrate transport and favor open channel states, suggesting a dynamic equilibrium between the two processes (Borre et al., 2002; Machtens et al., 2015; Torres-Salazar et al., 2015). The 
conclusions by Winter et al. (2012) harmonize with this idea.

In a recent publication in The Journal of Neuroscience, Parinejad et al. (2016) tested this hypothesis by creating a Drosophila model of ataxia expressing the EAAT1 P to R mutation (dEAAT1 ${ }^{\text {P243R }}$ ). The authors overexpressed the mutant dEAAT1 $^{\text {P243R }}$ or the homologous human EAAT1 ${ }^{\text {P290R }}$ (hEAAT1 ${ }^{\text {P290R }}$ ). Unlike overexpressing dEAAT1 ${ }^{\mathrm{WT}}$ (Stacey et al., 2010), overexpressing dEAAT1 ${ }^{\text {P243R }}$ or hEAAT1 $^{\text {P290R }}$ in the null mutant background did not rescue normal larval peristaltic behavior, suggesting that the mutation renders EAAT1 nonfunctional in vivo. When the mutant dEAAT1 ${ }^{\mathrm{P} 243 \mathrm{R}}$ was overexpressed in wild-type larvae, moreover, the animals exhibited episodes of complete paralysis during which they were unresponsive to mechanical stimulation. Notably, the episodes of immobility in the dEAAT1 ${ }^{\text {P243R }}$ mutants were significantly more frequent and more prolonged than in control groups, consistent with the idea that expressing the chloride channel gain-of-function mutation generates ataxia. Furthermore, when the dEAAT1 ${ }^{\text {P243R }}$-expressing larvae were mobile, they attained maximum speeds comparable with those of the control groups, suggesting that the neuronal circuitry responsible for peristalsis was intact. Additional findings revealed that, unlike complete knock-out of EAAT1, the dEAAT1 ${ }^{\text {P243R }}$ mutation significantly reduced astrocyte infiltration of the CNS neuropil. Because episodes of paralysis and reduced astrocyte infiltration were observed in dEAAT1 ${ }^{\mathrm{P} 243 \mathrm{R}}$ mutants but not in the EAAT1 ${ }^{\mathrm{KO}}$, the authors concluded that increased anion permeation, rather than reduced glutamate transport, was responsible for the significant differences in phenotypes between the two model systems (Parinejad et al., 2016).

The authors corroborated this conclusion by overexpressing the $\mathrm{K}^{+}-\mathrm{Cl}^{-}$cotransporter (KCC), which is responsible for chloride extrusion from the cell. Interestingly, overexpressing the Drosophila KCC (KccB) had effects similar to those overexpressing dEAAT1 $^{\text {P243R }}$ or hEAAT1 ${ }^{\text {P290R }}$, namely, decreased astrocyte infiltration of the CNS neuropil and episodic paralysis. These results support the hypothesis that the anion channel gain of function is the main contributor to the observed episodic ataxia.

To further support this conclusion, Parinejad et al. (2016) overexpressed the Drosophila $\mathrm{Na}^{+}-\mathrm{K}^{+}-\mathrm{Cl}^{-}$cotransporter (Ncc69), which mediates chloride uptake, and found effects opposite to those of KccB overexpression. Ncc69 overexpression caused a $20 \%$ increase in neuropil infiltration by astrocytes and significantly increased locomotor activity compared with wild-type. Even more compellingly, simultaneous expression of Ncc69 cotransporters with dEAAT1 ${ }^{\text {P243R }}$ rescued both neuropil infiltration and locomotor performance, preventing episodes of paralysis. These results provide convincing evidence that the enhanced chloride channel activity resulting from the dEAAT1 ${ }^{\text {P243R }}$ mutation is responsible for episodic paralysis in the mutant Drosophila. This is further supported by the observation of episodic paralysis in EAAT1 ${ }^{\text {P243R }}$ mutants, but not in EAAT1 ${ }^{\mathrm{KO}}$ larvae. The authors speculate that, because the mutation would eventually alter chloride osmotic balance, this could lead to astrocyte volume reduction and consequent withdrawal of their infiltrative processes. This is an appealing idea, considering the significant reduction in neuropil infiltration observed in the larvae expressing the mutant transporter.

Although the data provide strong support for the hypothesis that disruption of chloride permeation by the dEAAT1 ${ }^{\text {P243R }}$ mutation is responsible for the observed phenotypes, these findings could be further explored to fully characterize the relationship between this mutant transporter and the observed morphological and behavioral alterations. For example, there is no direct measurement of astrocyte intracellular chloride concentration $\left(\left[\mathrm{Cl}^{-}\right]_{\mathrm{i}}\right)$ and/or astrocyte membrane potential. If the episodes of paralysis are caused solely by the reduced $\left[\mathrm{Cl}^{-}\right]_{\mathrm{i}}$ resulting from excessive chloride efflux, changes in $\left[\mathrm{Cl}^{-}\right]_{\mathrm{i}}$ should be detectable using available chloride biosensors (Watts et al., 2012) or chloride-sensitive microelectrodes (Kettenmann et al., 1987). Measurement of astrocytes' membrane potential could also indicate changes in $\left[\mathrm{Cl}^{-}\right]_{\mathrm{i}}$. This is important because significant reductions in intracellular chloride would not only affect astrocyte morphology, but also modify the voltage dependence of potassium channels (Bekar et al., 2005), which contribute to the hyperpolarized resting membrane potential and other cellular processes in astrocytes (Olsen, 2012).

Future work should also assess the mechanism by which overexpression of Ncc69 rescues the dEAAT1 ${ }^{\text {P243R }}$ phenotype. Whereas Ncc69 moves chloride against its concentration gradient through a coupled active transport mechanism (Leiserson et al., 2011), EAATs facilitate chloride movement by simple diffusion down its concentration gradient through an anion-selective channel pore (Fahlke et al., 2016). Although EAAT-associated anion channels are categorized as slow ion channels with an estimated conductance of $\sim 1 \mathrm{pS}$, they are at least an order of magnitude faster than transporters, such as Ncc69 (Fahlke et al., 2016). It is therefore somewhat surprising that the much slower Ncc69 chloride influx could compensate for the significantly more rapid efflux associated with the dEAAT1 ${ }^{\text {P243R }}$ chloride channel. A much higher expression of Ncc69 compared with dEAAT1 ${ }^{\text {P243R }}$ would explain this discrepancy. However, we consider other alternative explanations. Notably, expression of endogenous EAAT1, which was significantly reduced when dEAAT1 ${ }^{\text {P243R }}$ was overexpressed, was restored when Ncc69 was coexpressed with dEAAT1 ${ }^{\text {P243R }}$. The endogenous EAAT1 would be expected to compete with dEAAT1 $^{\text {P243R }}$ and influence its recruitment to the plasma membrane. A reduction in membrane expression of dEAAT1 ${ }^{\text {P243R }}$ caused by increased endogenous EAAT1 might therefore explain the recovery of the normal phenotype. Another possible explanation for Ncc69's ability to rescue the dEAAT1 ${ }^{\text {P243R }}$ phenotype is that an unidentified "third party" molecule is at play. Such a molecule might be affected by the local increase in extracellular chloride concentration and trigger episodic ataxia. The addition of Ncc69 would prevent the presumed local extracellular chloride levels from reaching the minimal threshold necessary to activate such a molecule, thus preventing the episodic ataxia phenotype. These are intriguing questions that, when addressed in future studies, will help explain the capability of Ncc69 to compensate for the increased chloride efflux induced by the dEAAT1 ${ }^{\text {P243R }}$ mutation.

In conclusion, the studies by Parinejad et al. (2016) show that a single amino acid substitution in the glial isoform of the glutamate transporter, EAAT1, results in increased chloride permeation, which causes neural circuit dysfunction and ultimately produces episodic paralysis in Drosophila larvae. Future studies to identify changes in both extracellular and intracellular chloride concentrations will further illuminate how the EAAT1mediated anion channel is involved in behavioral phenotypes. This work also illustrates the importance of EAAT1associated anion conductance for normal astrocytic function. Moreover, it offers strong evidence that this EAAT function 
correlates with neuropathology, setting the stage for new studies that will help elucidate its role in the normal operation of the brain and in other neuropathological processes.

\section{References}

Bekar LK, Loewen ME, Forsyth GW, Walz W (2005) Chloride concentration affects Kv channel voltage-gating kinetics: importance of experimental anion concentrations. Brain Res Bull 67:142-146. CrossRef Medline

Bergles DE, Diamond JS, Jahr CE (1999) Clearance of glutamate inside the synapse and beyond. Curr Opin Neurobiol 9:293-298. CrossRef Medline

Borre L, Kavanaugh MP, Kanner BI (2002) Dynamic equilibrium between coupled and uncoupled modes of a neuronal glutamate transporter. J Biol Chem 277:13501-13507. CrossRef Medline

Danbolt NC (2001) Glutamate uptake. Prog Neurobiol 65:1-105. CrossRef Medline

Fahlke C, Kortzak D, Machtens JP (2016) Molecular physiology of EAAT anion channels. Pflugers Arch 468:491-502. CrossRef Medline

Fairman WA, Vandenberg RJ, Arriza JL, Kavanaugh MP, Amara SG (1995) An excitatory amino-acid transporter with properties of a ligand-gated chloride channel. Nature 375:599-603. CrossRef Medline

Jen JC, Wan J, Palos TP, Howard BD, Baloh RW (2005) Mutation in the glutamate transporter EAAT1 causes episodic ataxia, hemi- plegia, and seizures. Neurology 65:529-534. CrossRef Medline

Kettenmann H, Backus KH, Schachner M (1987) $\gamma$-Aminobutyric acid opens $\mathrm{Cl}^{-}$channels in cultured astrocytes. Brain Res 404:1-9. CrossRef Medline

Leiserson WM, Forbush B, Keshishian H (2011) Drosophila glia use a conserved cotransporter mechanism to regulate extracellular volume. Glia 59:320-332. CrossRef Medline

Machtens JP, Kortzak D, Lansche C, Leinenweber A, Kilian P, Begemann B, Zachariae U, Ewers D, de Groot BL, Briones R, Fahlke C (2015) Mechanisms of anion conduction by coupled glutamate transporters. Cell 160:542-553. CrossRef Medline

Nakagawa T, Kaneko S (2013) SLC1 glutamate transporters and diseases: psychiatric diseases and pathological pain. Curr Mol Pharmacol 6:66-73. CrossRef Medline

Olsen M (2012) Examining potassium channel function in astrocytes. Methods Mol Biol 814: 265-281. CrossRef Medline

Parinejad N, Peco E, Ferreira T, Stacey SM, van Meyel DJ (2016) Disruption of an EAATmediated chloride channel in a Drosophila model of ataxia. J Neurosci 36:7640-7647. CrossRef Medline

Picaud S, Larsson HP, Wellis DP, Lecar H, Werblin F (1995) Cone photoreceptors respond to their own glutamate release in the tiger salamander. Proc Natl Acad Sci U S A 92: 9417-9421. CrossRef Medline

Robinson MB, Jackson JG (2016) Astroglial glutamate transporters coordinate excitatory sig- naling and brain energetics. Neurochem Int 98:56-71. CrossRef Medline

Stacey SM, Muraro NI, Peco E, Labbé A, Thomas GB, Baines RA, van Meyel DJ (2010) Drosophila glial glutamate transporter Eaat1 is regulated by fringe-mediated notch signaling and is essential for larval locomotion. J Neurosci 30:14446-14457. CrossRef Medline

Torres-Salazar D, Jiang J, Divito CB, GarciaOlivares J, Amara SG (2015) A mutation in transmembrane domain 7 (TM7) of excitatory amino acid transporters disrupts the substrate-dependent gating of the intrinsic anion conductance and drives the channel into a constitutively open state. J Biol Chem 290:22977-22990. CrossRef Medline

Veruki ML, Mørkve SH, Hartveit E (2006) Activation of a presynaptic glutamate transporter regulates synaptic transmission through electrical signaling. Nat Neurosci 9:1388-1396. CrossRef Medline

Watts SD, Suchland KL, Amara SG, Ingram SL (2012) A sensitive membrane-targeted biosensor for monitoring changes in intracellular chloride in neuronal processes. PLoS One 7:e35373. CrossRef Medline

Wersinger E, Schwab Y, Sahel JA, Rendon A, Pow DV, Picaud S, Roux MJ (2006) The glutamate transporter EAAT5 works as a presynaptic receptor in mouse rod bipolar cells. J Physiol 577:221-234. CrossRef Medline

Winter N, Kovermann P, Fahlke C (2012) A point mutation associated with episodic ataxia 6 increases glutamate transporter anion currents. Brain 135:3416-3425. CrossRef Medline 